\title{
Comparative Study on Occupant Evacuation with Building EXODUS and a Cellular Automaton Model
}

\author{
Daoliang Zhao*, Batyr Yegenmammedov, Peichen Liu, Meiting Zhang \\ College of Urban Construction and Safety Engineering, Shanghai Institute of Technology, Shanghai, China \\ Email: *zhaodl@sit.edu.cn, 841658234@qq.com
}

How to cite this paper: Zhao, D.L., Yegenmammedov, B., Liu, P.C. and Zhang, M.T. (2017) Comparative Study on Occupant Evacuation with Building EXODUS and a Cellular Automaton Model. Open Journal of Safety Science and Technology, 7, 42-57.

https://doi.org/10.4236/ojsst.2017.71004

Received: November 4, 2016

Accepted: March 25, 2017

Published: March 28, 2017

Copyright $\odot 2017$ by authors and Scientific Research Publishing Inc. This work is licensed under the Creative Commons Attribution International License (CC BY 4.0).

http://creativecommons.org/licenses/by/4.0/

(c) (i) Open Access

\begin{abstract}
Building EXODUS software is used to calculate the evacuation times and simulate the evacuation behavior. The results and laws are compared with those from a 2D Cellular Automaton (CA) random evacuation model developed by our group. EXODUS simulation is more reasonable than the CA simulation in the case of evacuation from a simple room, but CA model is more reasonable in the case of evacuation in a long corridor after bottlenecks. As far as the evacuation from a simple room with a single exit is concerned, there is a critical value of exit width. The value of exit width should be bigger than the critical value in order to ensure a dilute pedestrian flow, but the value doesn't need to be too big. The bigger the original occupant density, the longer the evacuation time is. They can be fitted as a linear relationship. The principle of taking the shortest route is not always useful. If the distribution of occupant density is not uniform at each building part, balancing the use efficiency of each exit should be the main principle in order to improve evacuation efficiency. All the above laws can be obtained both from EXODUS and the CA model.
\end{abstract}

\section{Keywords}

Occupant Evacuation, Building EXODUS, Cellular Automata

\section{Introduction}

Available Safe Egress Time (ASET) and Required Safe Egress Time (RSET) are two important elements in evacuation evaluation. ASET is determined by the evolvement of disasters, which is not discussed within this paper. RSET is composed of detection and alarm time, pre-movement time [1] [2] [3] and occupant movement time. Pre-movement time is related to the type of building and occu- 
pant, the mode of fire, the state of occupants, and etc. Fahy et al. deem that Weibull distribution is very suitable to describe pre-movement time [4], which ranges from several seconds to a few 10 minutes. This study only focuses on occupant movement time i.e. detection and alarm time, pre-movement time are not considered.

At present, many researchers are committed to develop empirical formulas and models on evacuation movement time. Familiar empirical formulas are Togawa formulas applied on engineering calculation of densely occupied public site [5], Melinek and Booth formulas applied on the calculation of the shortest evacuation time of high-rise buildings [6], Pauls formulas applied on the calculation of the evacuation time of staircases [7], and the method put forward by Nelson et al. (NFPA) based on the research work of Pauls, Proulx, Predtechenskii and Milinskii [8]. Familiar models involve continuous models and discrete models. Representational continuous models are social force model by Helbing [9], magnetic force model by Okazaki [10], and hydrodynamic model by Henderson and Hughes [11] [12], network model and affordance-based finite state automata model [13] [14]. Representational discrete models are cellular automaton models [15] [16] [17] [18], lattice gas models [19] [20], agent-based models [21] [22] and floor field models [23].

Jamming is easily happened in evacuation crowd with high density, especially at narrow and long passages, doorways, stairs, etc. The pedestrian flow can change from a lamina flow to a stop-and-go wave, and then to a turbulent flow with the increase of density. Panicking individuals in evacuation tend to show maladaptive behavior like jamming and life-threatening overcrowding. The physical interactions in the jammed crowd add up and cause dangerous pressures up to $4450 \mathrm{~N} / \mathrm{m}$ which can bend steel barriers or push down brick walls. Escape is slowed by fallen or injured people acting as obstacles. In addition, backtracking and counterflows, overtaking behavior, sub-group phenomenon etc. are also studied by many researchers.

Simulation of occupant behavior during evacuation is very complex and not all the behaviors can be quantified. Apparently models including more rules have become a trend. In this paper, the software of building EXODUS developed by the University of Greenwich is applied to analyze the influence of occupant density, exit width and exits distribution on evacuation. The results are compared with those of a 2D cellular automaton model developed by ourselves. Only simple rooms without obstacles are considered in this study.

\section{Model Description}

The common ground on EXODUS and our CA model can be summarized as below: 1) They are discrete models taking into consideration people-people, people-fire and people-structure interactions; 2) They have been written in C++ using Object Orientated techniques and rule-base concepts to control the simulation; 3) Building structure is represented by a two-dimensional grid. Each node represents $0.5 \mathrm{~m} \times 0.5 \mathrm{~m}$, which can hold only one person. 


\subsection{Building EXODUS Model}

The rules of building EXODUS (V6.1) [24] can be categorized into five interacting sub-models, the OCCUPANT, MOVEMENT, BEHAVIOUR, TOXICITY and HAZARD sub-models. The last two sub-models are not used in this study. We only introduce the rules and attributes concerning route selection. The database system of building EXODUS can provide reliable parameters about occupant attribute, building geometry, evacuation environment and so on. For more details, please refer to the user guide and technical manual of EXODUS.

Geometries are represented as two-dimensional grids. Each location on a grid is called a node, and each node may be linked to its nearest neighbors by four or eight arcs as shown in Figure 1. Occupants can move along those arcs from node to node. Walking speed and direction can be adjusted according to the change of environment, such as the crowd density and the distribution of obstacles. Occupants always move from the node of high danger grade to the node of low danger grade and eventually toward the exits.

The OCCUPANT sub-model defines each individual as a collection of attributes which broadly fall into four categories, physical, psychological, experiential and hazard effects. The Target Door attribute allows an occupant to be directed to a specific external door, regardless of the potential map. The values this attribute may take are the names of the exits in the geometry. The default value is "Nearest Door", i.e. follow the potential map, which is applied in this paper.

The MOVEMENT sub-model controls the physical movement of individual occupants from their current position to the most suitable neighboring location, or supervises the waiting period if one does not exist. The movement may involve such behavior as overtaking, sidestepping, or other evasive actions controlled by the BEHAVIOR sub-model.

\subsection{CA Model}

Von Neumann neighborhood is applied to consider four possible movement directions, i.e. up and down, left and right. In each time step, there are two basic problems to be resolved, i.e. route selection and conflict resolution. Each occupant checks all the cells within visual field and selects a proper target cell according to the value of $p_{i j}$ determined by the following formula:
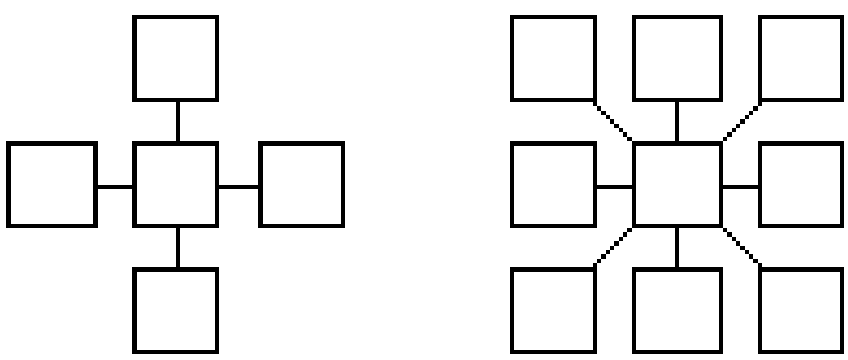

Figure 1. Connection mode of cells in EXODUS. 


$$
p_{i j}=N \exp \left(k_{S} S_{i j}\right) \exp \left(k_{F} F_{i j}\right) \exp \left(k_{R} R_{i j}\right) \exp \left(k_{A} A_{i j}\right) \exp \left(k_{D} D_{i j}\right)\left(1-n_{i j}\right)
$$

where $p_{i j}$ denotes the probability of moving to the cell $(i, j) ; n_{i j}=1$ denotes that the cell $(i, j)$ is occupied by an occupant at the time of $t$, otherwise, $n_{i j}$ $=0$; the parameter $\mathrm{N}$ is introduced:

$$
N=\left[\sum_{(i, j)} \exp \left(k_{S} S_{i j}\right) \exp \left(k_{F} F_{i j}\right) \exp \left(k_{A} A_{i j}\right) \exp \left(k_{D} D_{i j}\right)\left(1-n_{i j}\right)\right]^{-1}
$$

where $S_{i j}$ and $k_{S}$ denote position attraction and its influence coefficient of cell $(i, j)$, respectively; $R_{i j}$ and $k_{R}$ denote repulsive force of occupants around and its influence coefficient of cell $(i, j)$, respectively; $A_{i j}$ and $k_{A}$ denote attraction of occupants around and its influence coefficient of cell $(i, j)$, respectively; $D_{i j}$ and $k_{D}$ denote attraction of movement direction and its influence coefficient of cell $(i, j)$, respectively; $F_{i j}$ and $k_{F}$ denote fire repulsive force and its influence coefficient of cell $(i, j)$, respectively; where, $k_{S}, k_{A}, k_{D} \geq 0$, $k_{F}, k_{R} \leq 0$. In this paper, $k_{F}=0 . D_{i j}$ and $A_{i j}$ reflect the psycho- logy of going with the crowd or the kin behavior. The adjacent occupants form $R_{i j}$ in order to avoid colliding with each other.

$S_{i j}$ is determined by the choice of safety exits. It reflects the geometry of the structure and the locations of the exits. In general, the nearer to the exit, the greater the value of the cell is. The simple formula is:

$$
\begin{aligned}
S_{i j}= & \max _{(i, j)}\left\{\min _{\left(i e_{k}, j e_{k}\right)}\left\{\sqrt{\left(i e_{k}-i\right)^{2}+\left(j e_{k}-j\right)^{2}}\right\}\right\} \\
& -\min _{\left(i e_{k}, j e_{k}\right)}\left\{\sqrt{\left(i e_{k}-i\right)^{2}+\left(j e_{k}-j\right)^{2}}\right\}
\end{aligned}
$$

where $\left(i e_{k}, j e_{k}\right)$ denotes the coordinates of each exit. The second item on the right of the equation denotes the minimum of the distance between $(i, j)$ and each exit. The first item is the maximum of the above values.

A set of intelligent local rules are introduced into the model: 1) Determine the probability of each adjacent cell based on Equations (1)-(3). 2) Each occupant chooses one of the adjacent cells as its object at the next time step depending on the probability of each cell in its visual field. 3) For each cell where more than one occupant want to enter, randomly assign it to one of them with a certain probability; other occupants still stay where they are. In this paper, we consider that every competitor has the same probability. 4) In order to avoid a determinate model, a random slowdown rule is introduced: Give each occupant who has decided to move a probability to stay. An experiential value, $5 \%$, is used here because it's most close to real data. 5) After parallel updating each occupant in each time- step, compute each cell's probability if necessary. 6) Do the above until all the occupants finish their evacuation. For more details, please refer to our previous work [25] [26] [27] [28].

\section{Comparative Study between EXODUS and the CA Model}

\subsection{Randomicity}

A case of a $30 \times 30$ (i.e. $15 \mathrm{~m} \times 15 \mathrm{~m}$ ) room with a single exit located at the mid- 
dle of the wall are simulated by both EXODUS and the CA model. Exit width $d$ equals 3, i.e. $1.5 \mathrm{~m}$, and 600 occupants randomly located in the beginning. The results are shown in Tbl.1. In the CA model, each time step (ts) represents different real time based on walking velocity and the size of a cell. By experience, 1 ts represents $0.66 \mathrm{~s}$ (walking velocity is $0.76 \mathrm{~m} / \mathrm{s}$, the length of a cell is $0.5 \mathrm{~m}$, $0.5 / 0.76 \approx 0.66 \mathrm{~s}$ ).

The mean values of evacuation time by EXODUS and the CA model are $325.67 \mathrm{~s}$ and $325.45 \mathrm{~s}$ (i.e. $493.1 \times 0.66=325.45 \mathrm{~s}$ ), respectively. The relative deviations of the CA model are slightly bigger than those of EXODUS as shown in Table 1. For the accuracy of the data, all the results in this paper are the mean values of 10 times calculation in the same condition.

\subsection{Intelligence}

The different intelligence and pedestrian flow configuration of building EXODUS and our CA model are shown by three examples.

\subsubsection{Case One}

Occupant distribution states of EXODUS and the CA model during evacuation process are very different as shown in Figure 2. In our CA model, all occupants form an assembling state around the exit very quickly, while only the occupants around the exit form an assembling state and the occupants away from the exit almost keep still at the initial stage in EXODUS. EXODUS is able to represent the delay that evacuees might experience before commencing their evacuation. This is attributed to each agent who then delays their response accordingly. By default, this ranges from 0 - 30 seconds. During the middle stage, occupants form a semicircle assembling state at the exit in EXODUS, and there are scarcely any interspaces. While occupants form a prolate assembling state and there are more interspaces in the CA model. EXODUS can more reasonably simulate the

Table 1. Results of EXODUS and the CA model $(30 \times 30$ room, $d=3,600$ occupants $)$.

\begin{tabular}{ccccc}
\hline $\begin{array}{c}\text { Simulation } \\
\text { times }\end{array}$ & $\begin{array}{c}\text { Evacuation time by } \\
\text { EXODUS }(\mathrm{s})\end{array}$ & $\begin{array}{c}\text { Relative } \\
\text { deviation }\end{array}$ & $\begin{array}{c}\text { Evacuation time by } \\
\text { the CA model (ts/s) }\end{array}$ & $\begin{array}{c}\text { Relative } \\
\text { deviation }\end{array}$ \\
\hline 1 & 325.9 & $+0.07 \%$ & $489 / 322.74$ & $-0.83 \%$ \\
2 & 323.8 & $-0.57 \%$ & $501 / 330.66$ & $+1.60 \%$ \\
3 & 322.6 & $-0.94 \%$ & $489 / 322.74$ & $-0.83 \%$ \\
4 & 322.9 & $-0.85 \%$ & $496 / 327.36$ & $+0.59 \%$ \\
5 & 324.4 & $-0.39 \%$ & $480 / 316.8$ & $-2.66 \%$ \\
6 & 329.4 & $+1.14 \%$ & $493 / 325.38$ & $-0.02 \%$ \\
7 & 322.4 & $-1.00 \%$ & $497 / 328.02$ & $+0.79 \%$ \\
8 & 329.1 & $+1.05 \%$ & $491 / 324.06$ & $-0.43 \%$ \\
9 & 329.9 & $+1.30 \%$ & $499 / 329.34$ & $+1.20 \%$ \\
10 & 326.3 & $+0.19 \%$ & $496 / 327.36$ & $+0.59 \%$ \\
Mean value & 325.67 & & $493.1 / 325.45$ & \\
Standard & 2.77 & & $5.82 / 3.84$ & \\
deviation & & & & \\
\hline
\end{tabular}


characteristic of assembling in the case of evacuation from a simply room because there are eight and four possible movement directions for each occupant in EXODUS and the CA model, respectively.

\subsubsection{Case Two}

Occupant evacuations from a room to a long corridor are simulated. The whole structure is a $20 \times 100$ area with a room of $20 \times 40$ and a total number of 371 occupants. Single door $(d=4)$ and two doors (each $d=2)$ are considered. As shown in Figure 3, compared with the CA simulation, only the middle one of three parts of the corridor is occupied after the bottleneck (door). In Figure 3 (b), the occupants form two separate pedestrian flows in the corridor in EXODUS simulation; while the occupants are almost evenly distributed at the whole width of the corridor and form a single pedestrian flow after the bottlenecks in the CA simulation. Our CA model is more reasonable in this case.

\subsubsection{Case Three}

Evacuation from a room with two exits and initially 130 occupants is simulated.

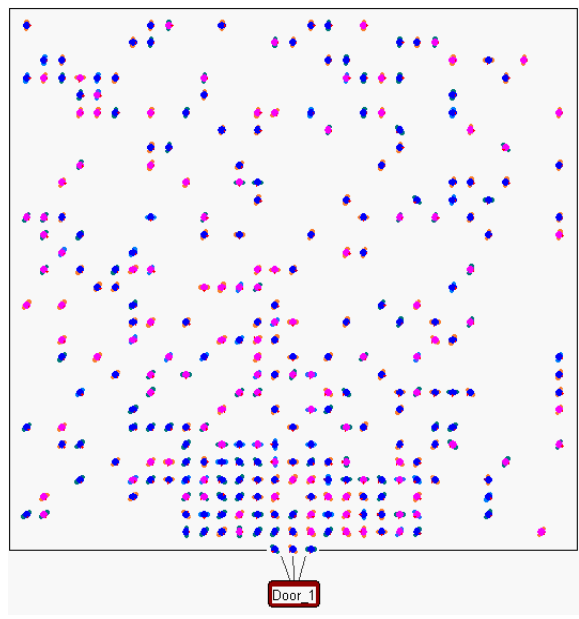

(a) $2.5 \mathrm{~s}$, EXODUS

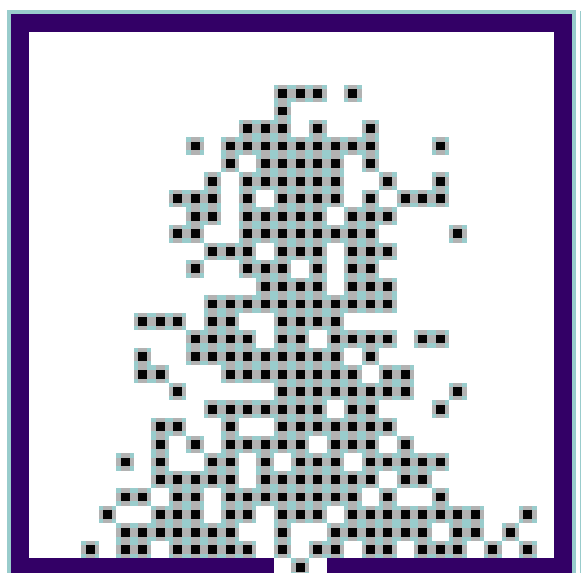

(c) $2.5 \mathrm{~s}, \mathrm{CA}$

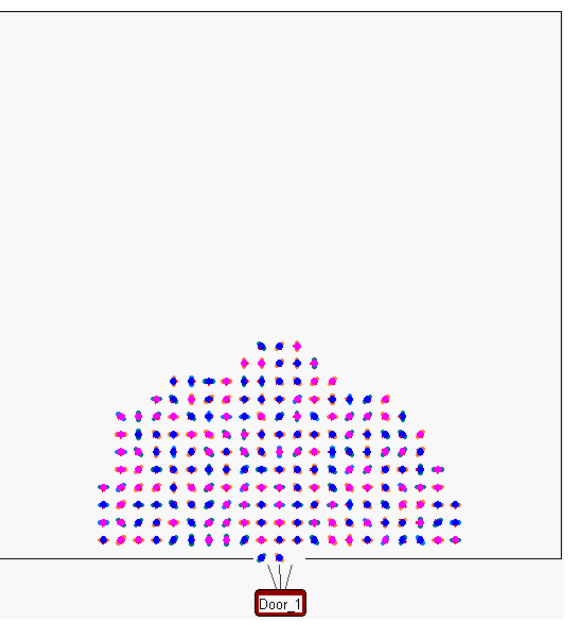

(b) $62.5 \mathrm{~s}$, EXODUS

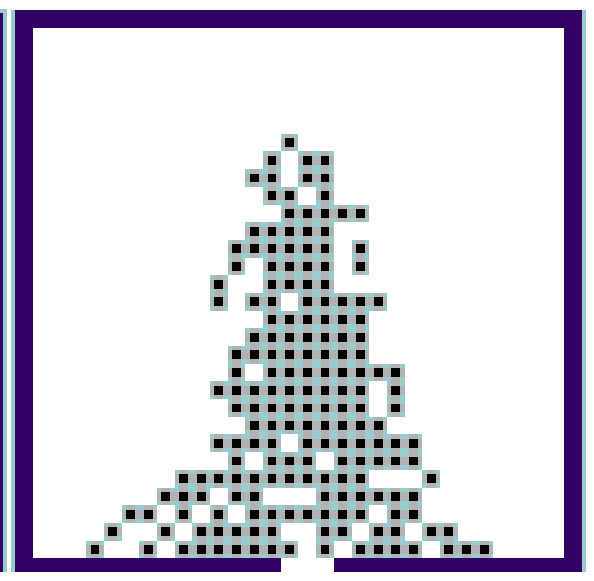

(d) $62.5 \mathrm{~s}, \mathrm{CA}$

Figure 2. Occupant distribution states at different times with initially 300 people in a square room. 


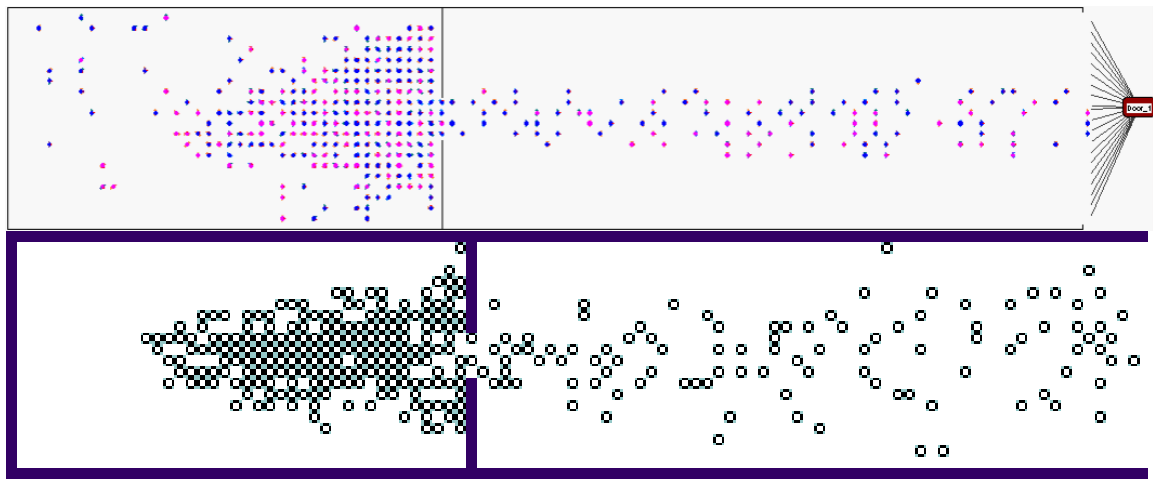

(a) Single door, $\mathrm{d}=4,100 \mathrm{~s}$

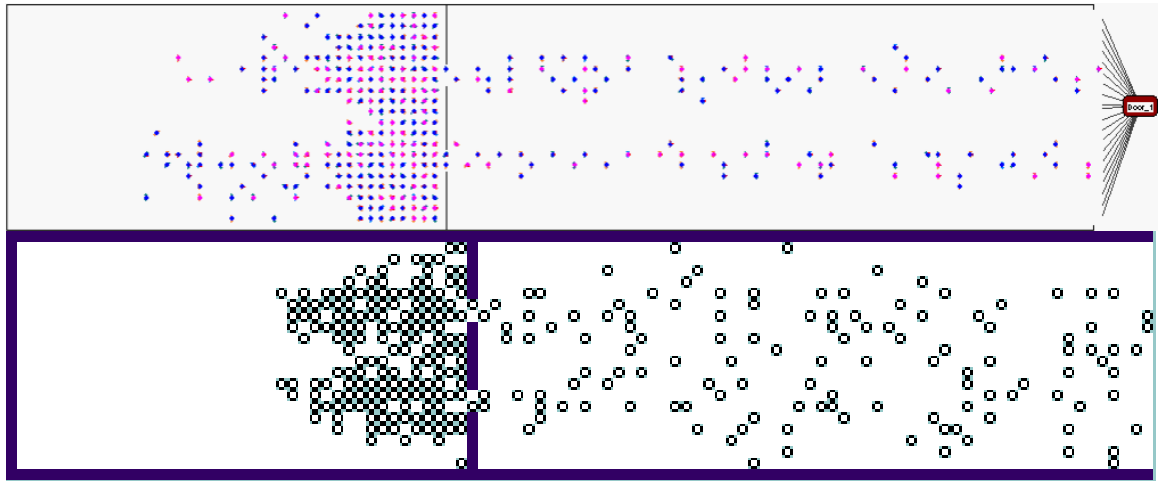

(b) Two doors, $\mathrm{d}=2,100 \mathrm{~s}$

Figure 3. Occupant distribution states in a long corridor after the bottlenecks.

As shown in Figure 4(a), the initial occupant density of the right part is about twice than that of the left part. In general, occupants try to evacuate form the nearer exit. At the initial stage (5 s), two separate pedestrian flows are formed at each exit. Soon afterwards, some occupants at the right part change their routes gradually and choose the left exit as their target. At $83 \mathrm{~s}$, evacuation is finished at the left exit, while there are still about 20 occupants queuing up at the right exit. So the total evacuation time is prolonged for the different use ratio (the number of occupants passing divided by exit width and evacuation time) of the exits. EXODUS takes on certain intelligence and the result of EXODUS is almost the same as the CA simulation with a visual field radius of 2 . The evacuation time of EXODUS and the CA model (the radius of visual field is 2) are $130.0 \mathrm{~s}$ and 133.8 $s$ respectively. In the CA model, the bigger the radius of visual field, the more reasonable route choice can be made and thus a shorter evacuation time is needed.

\subsection{Influence of Exit Width}

The physical distance between nodes is $0.5 \mathrm{~m}$, which is assumed as one unit. Each dimensionless size can be obtained by actual size divided by $0.5 \mathrm{~m}$. First of all, the parameters $d, q, \rho, t$ are interpreted as below: $d$ is dimensionless exit width, $q$ is flux per dimensionless unit exit width (people/s), $\rho$ is occupant density (the number of occupants divided by the number of nodes of the structure) and $t$ is evacuation time (s). 


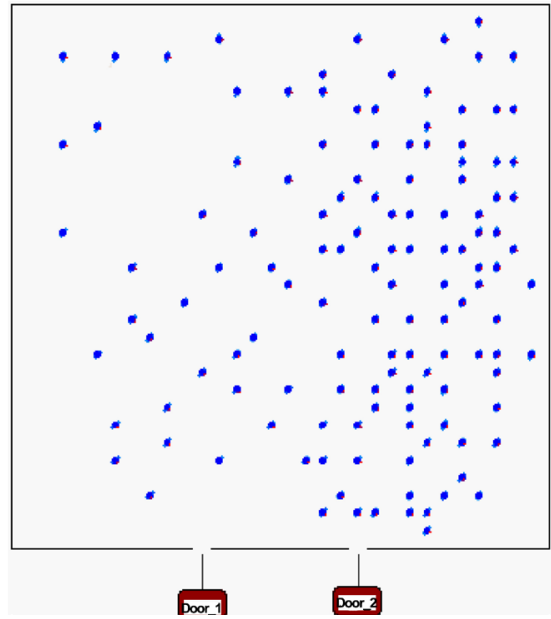

(a) $0 \mathrm{~s}$

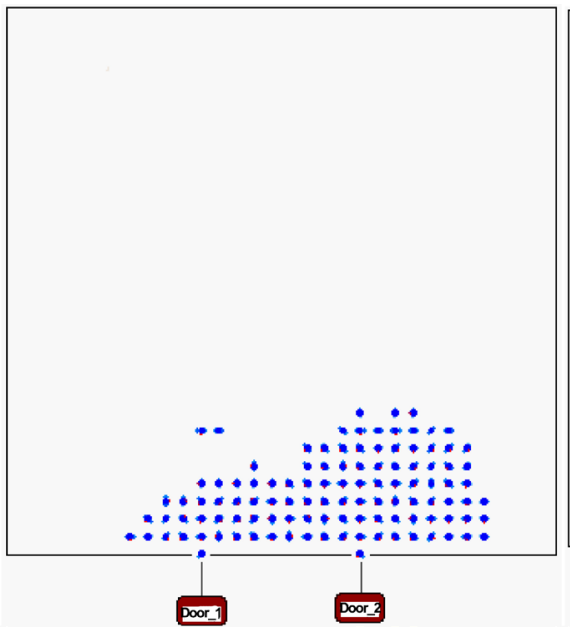

(c) $15 \mathrm{~s}$

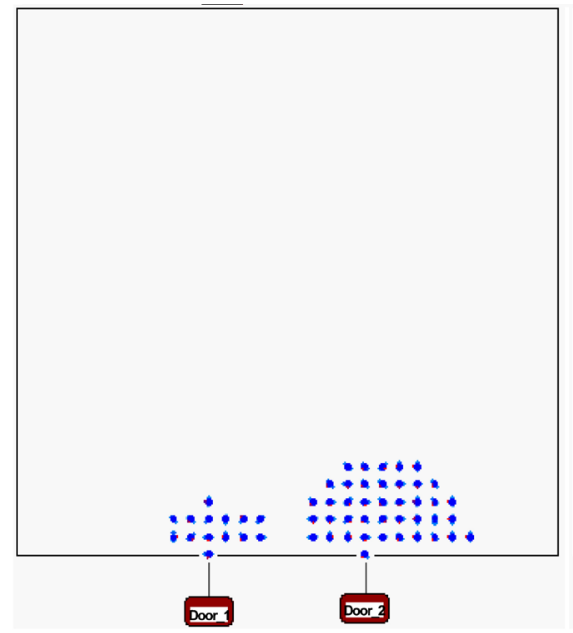

(e) $60 \mathrm{~s}$

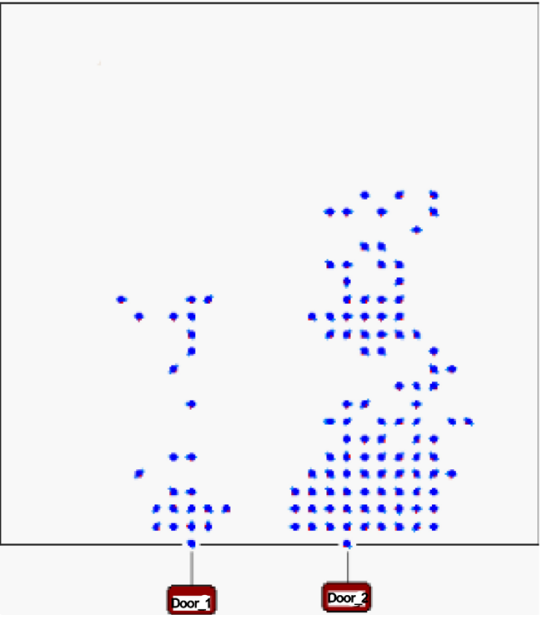

(b) $5 \mathrm{~s}$

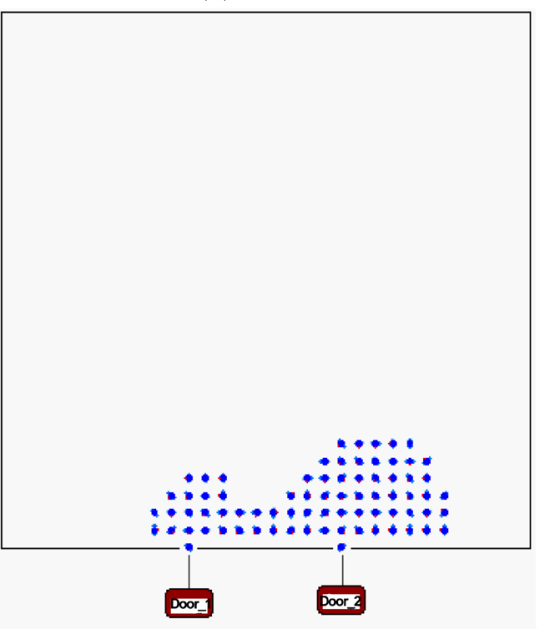

(d) $45 \mathrm{~s}$

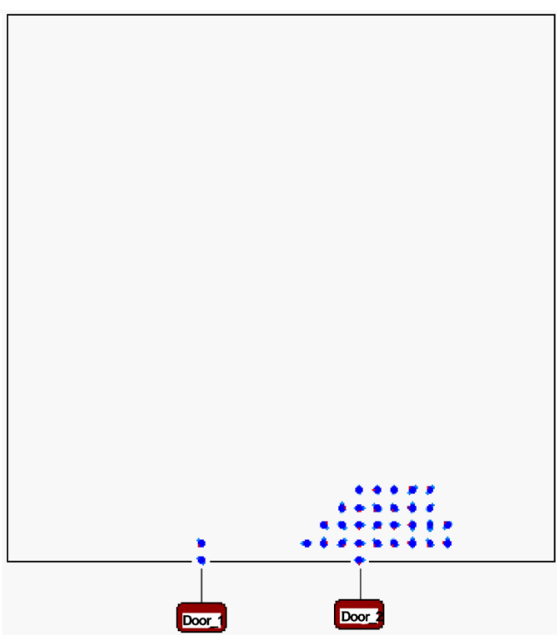

(f) $80 \mathrm{~s}$

Figure 4. Occupant distribution states at different times of case three.

\subsubsection{Case Four}

A room $(18 \times 14)$ that initially contains 200 randomly distributed occupants is calculated. As shown in Figure 5, the occupants and the exit door are purposely 


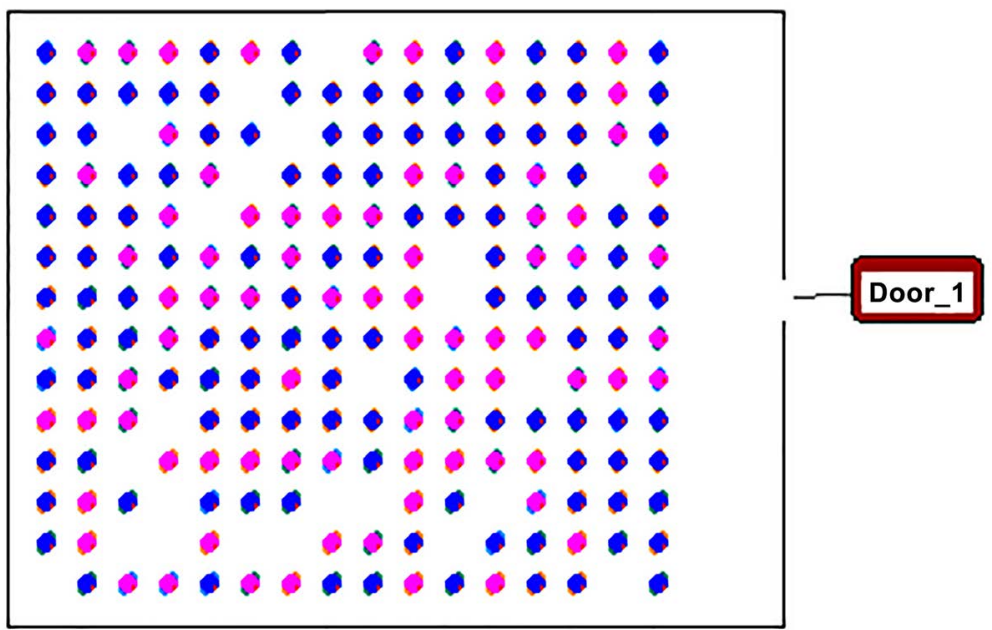

Figure 5. Initial state of case four $(18 \times 14,200$ occupants $)$.

separated by two rows of unfilled nodes to prevent the premature occurrence of jamming [25]. Figure 6 shows the results of EXODUS and the CA model.

We can see that $q$ decreases with the increase of $d$. By observing the dynamic play of EXODUS, we find that occupants form a stable and regular dense pedestrian flow state when $d$ is smaller than 4 , while the pedestrian flow takes on a dilute state when $d$ is bigger than 4 .

Evacuation time decreases nonlinearly with the increase of $d$. viz. when $d$ is small, increasing $d$ is very helpful for decreasing the evacuation time. When $\mathrm{d}$ is bigger than 4 , the evacuation time decreases very slowly; especially when $d$ is bigger than 8 , evacuation time is almost unchanged, and the use ratio of the door $(q)$ is very low. In this case, $d=4$ is regarded as the critical value.

\subsubsection{Case Five}

The room is sized $50 \times 50$ with 1365 occupants initially randomly distributed. The results are shown as Figure 7. Although, the size of the room and the density of the occupants are different with those of case four, the laws we obtained are the same. In this case, $d=10$ is regarded as the critical point.

As far as the evacuation form a simple room with a single exit is concerned, there is a critical value of exit width. In practice, the value of exit width should be bigger than this critical value in order to ensure a dilute pedestrian flow and a safe evacuation. Occupants need not to queue up at the exits when $d$ is bigger than the critical value. Considering the other factors such as the economy, the appearance, the structure safety and etc., it's no need to make the exits too big. We can obtain the same rules form EXODUS and the CA model, but the evacuation times of the CA model are slightly greater than those of EXODUS.

\subsection{Influence of Initial Occupant Density}

A room sized $18 \times 14$ with a single exit $(d=2)$ is calculated. As shown in Figure 8(a), when occupant density $\rho$ is smaller than $0.4, q$ increases with the increase of $\rho$, While $q$ changes a little (the flux of exit takes on a saturated state) when $\rho$ is 
greater than 0.4. We can get the same law from EXODUS and the CA model, but the values of $q$ in the CA simulation are bigger than those in EXODUS.

As shown in Figure 8(b), the bigger the occupant density, the longer the evacuation time is. The results can be linearly fitted as: $\mathrm{t}=205.263 \rho+3.635$ (EXODUS). The results of CA are slightly smaller than those of EXODUS. In practice, occupant density should be controlled to be less than 0.4 , i.e. 1.6 peo$\mathrm{ple} / \mathrm{m}^{2}$.

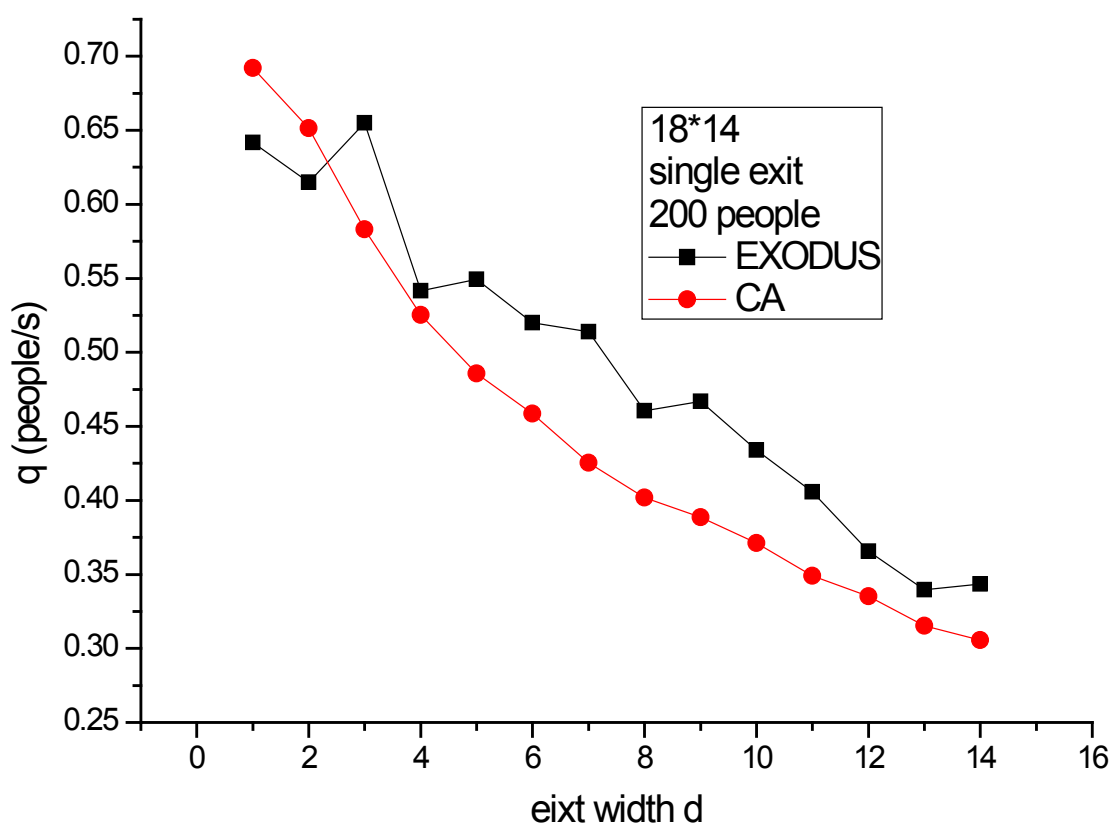

(a)

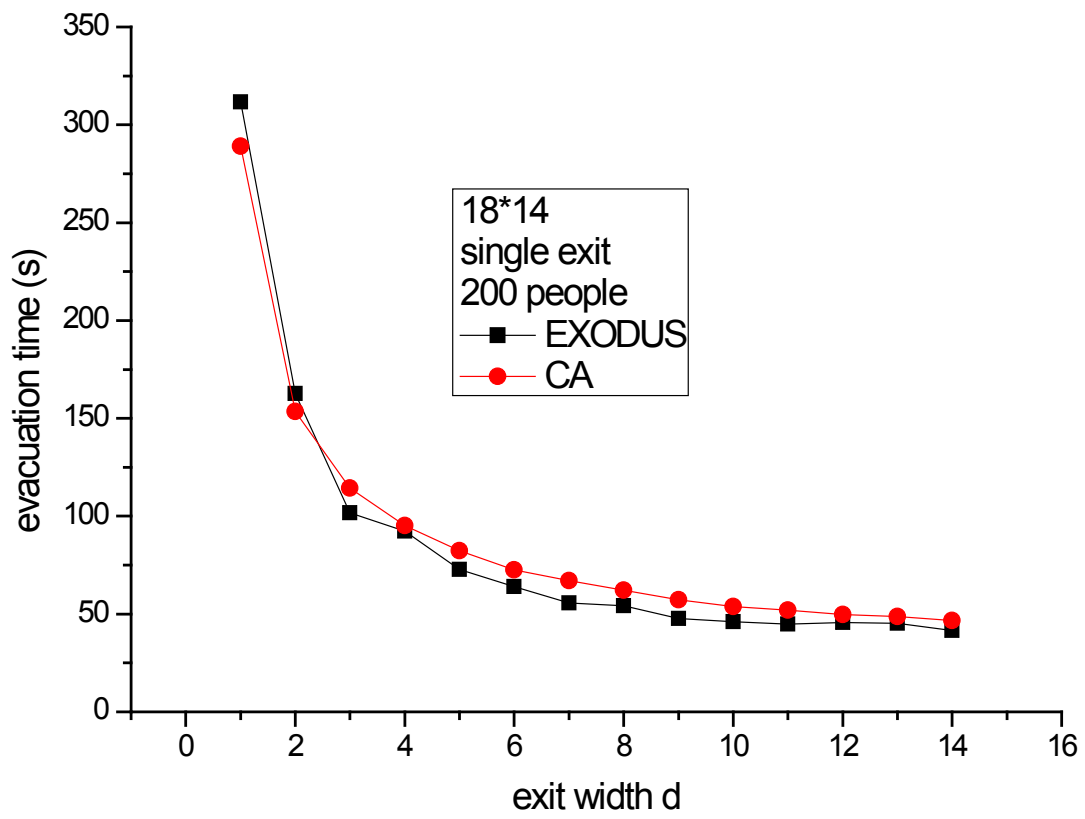

(b)

Figure 6. Results of case four, (a) Relations between $\mathrm{q}$ and d; (b) Relations between $\mathrm{t}$ and d. 


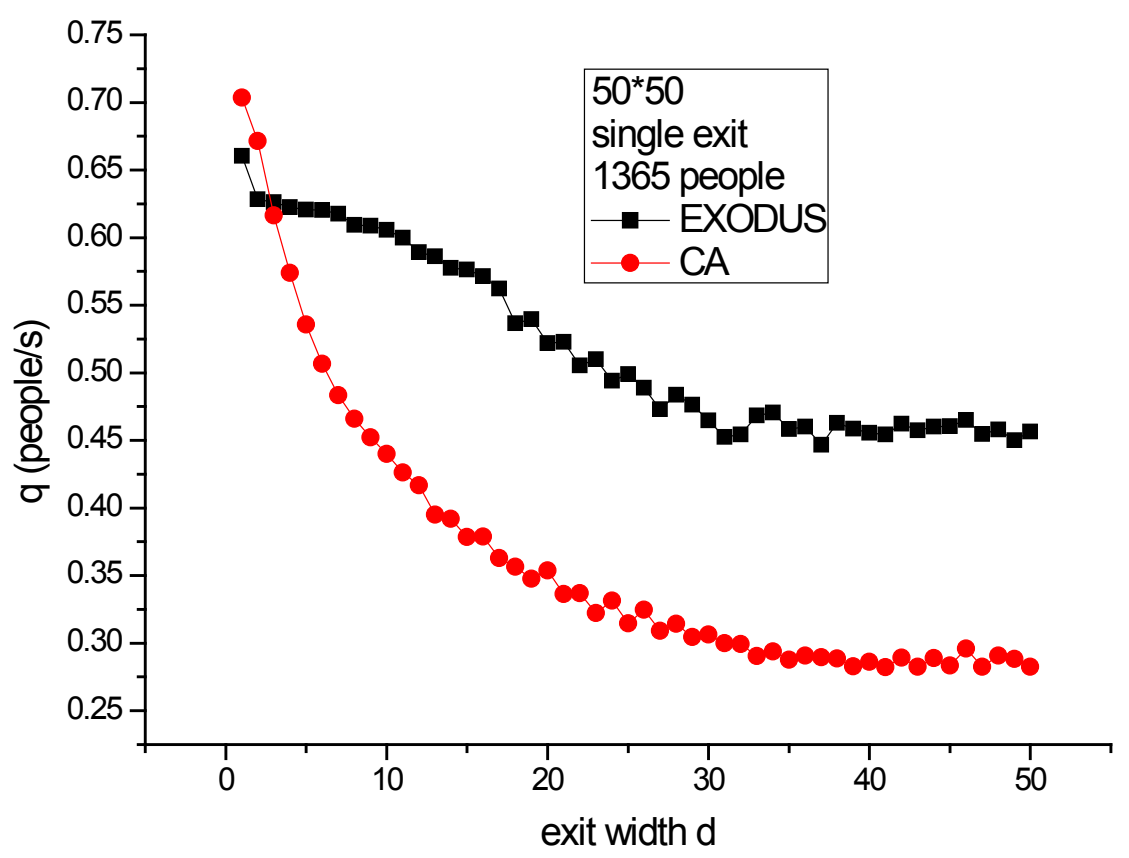

(a)

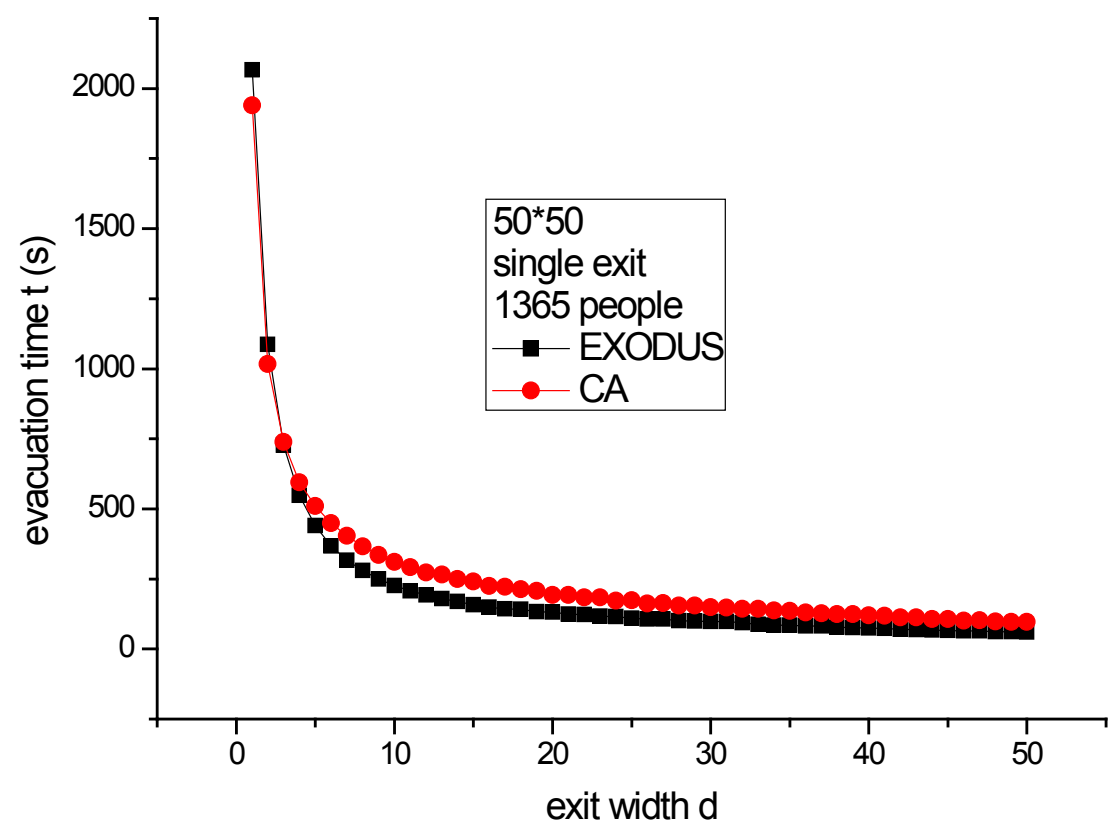

(b)

Figure 7. Results of case five, (a) Relations between $\mathrm{q}$ and d; (b) Relations between $\mathrm{t}$ and d.

\subsection{Influence of the Distribution of Exits}

A room sized $18 \times 14$ with two exits (each $d=2$ ) and initially 126 occupants is considered. Opposite and adjacent layout of exits (each exit is located in the middle of the wall) and different distribution of occupant density are discussed as shown in Figure 9. 


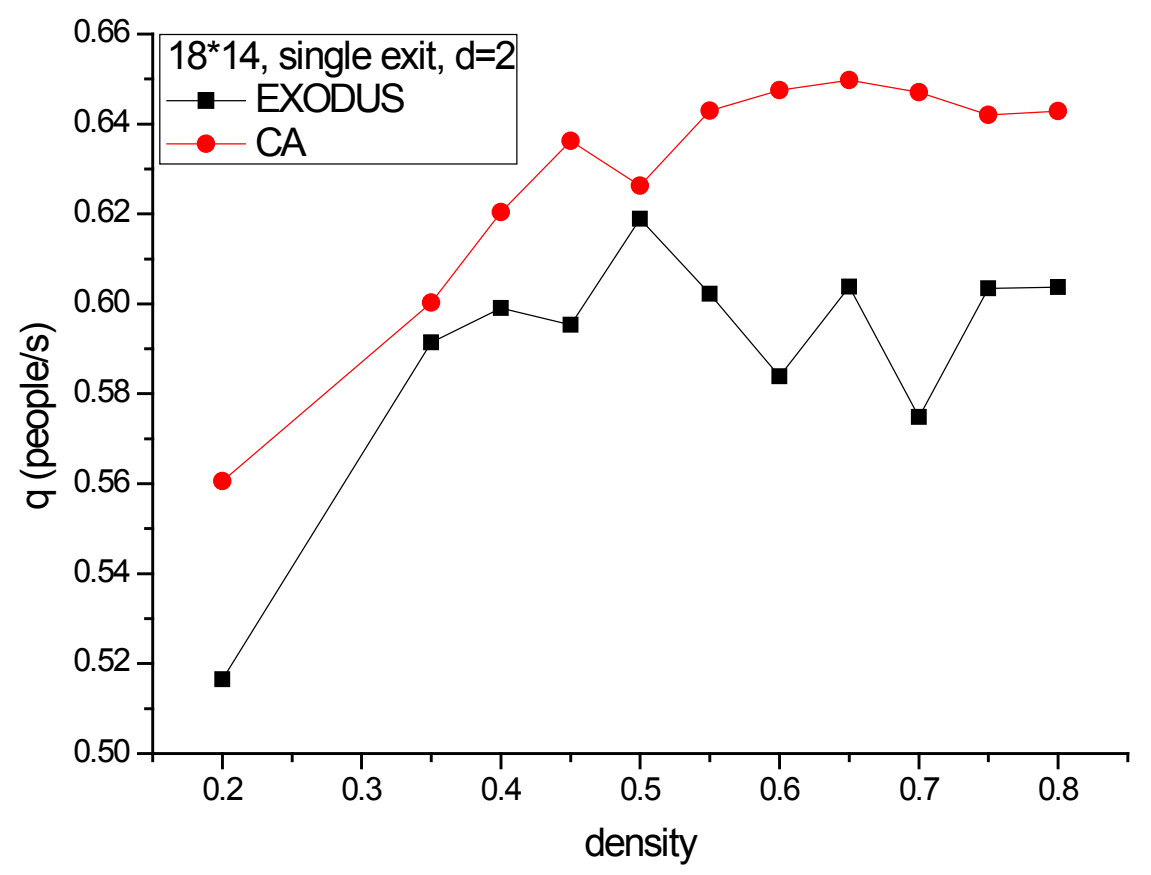

(a)

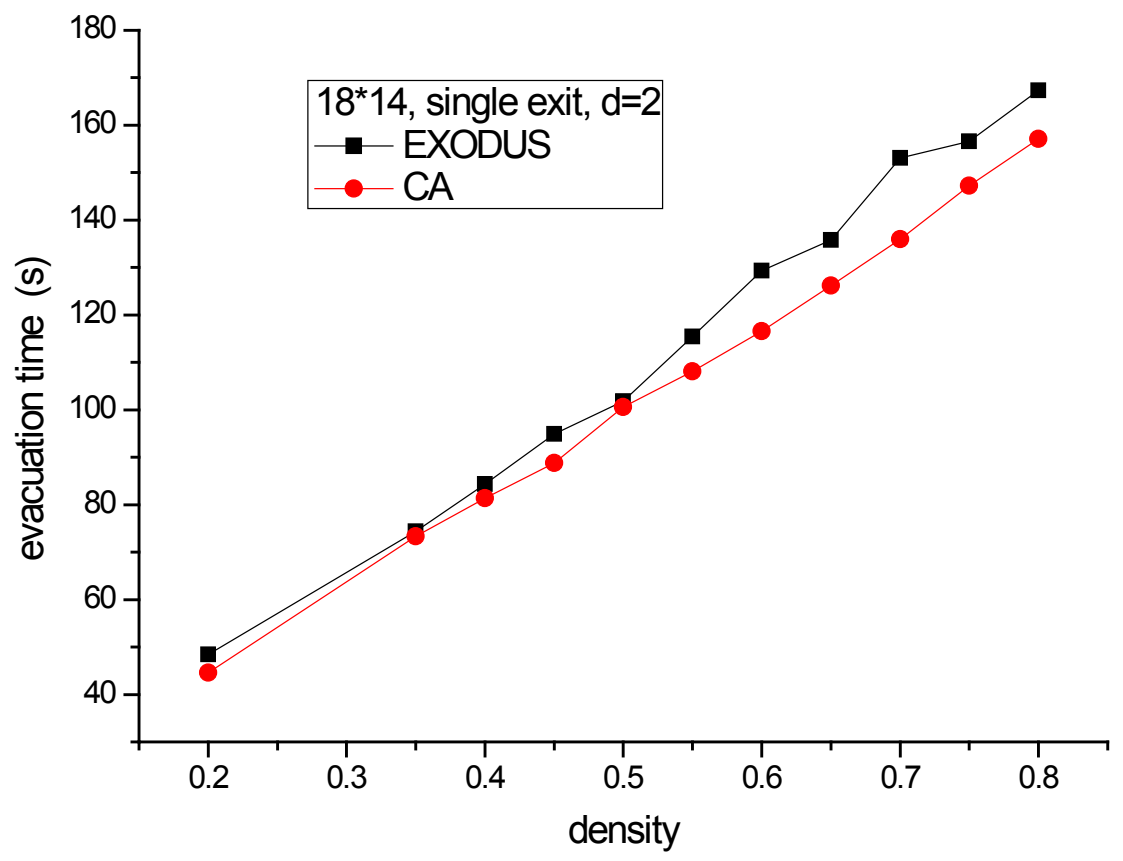

(b)

Figure 8. Results of evacuation with different density, (a) Relations between $q$ and $\rho$; (b) Relations between $t$ and $\rho$.

Because of the principle of following the potential map in EXODUS, almost all the occupants initially located at the left (right) part of the room choose the left (right) exit (Figure 9(b)). The occupant density of the right half part is twice than that of the left half part, so almost half occupants are still queuing up for evacuation when the left exit finishes evacuation. The evacuation time of the 
right exit (i.e. the total evacuation time) and the left exit are $75.6 \mathrm{~s}$ and $39 \mathrm{~s}$, respectively. The former is almost twice than the latter. In the CA simulation, the evacuation times of the right exit and the left exit are $62.9 \mathrm{~s}$ and $42.2 \mathrm{~s}$, respectively.

Corresponding to the four cases in Figure 9, the evacuation times simulated by EXODUS are $61.5 \mathrm{~s}, 75.6 \mathrm{~s}, 63.8 \mathrm{~s}$, and $79.1 \mathrm{~s}$, respectively. By the CA simulation, they are $55.8 \mathrm{~s}, 62.9 \mathrm{~s}, 53.1 \mathrm{~s}$, and $67.0 \mathrm{~s}$, respectively. Compared with EXODUS, the evacuation times by CA simulation are reduced by $9.3 \%, 16.8 \%$, $16.8 \%$, and $15.3 \%$, respectively. In the CA simulations, the principle of taking the shortest routes is not always been applied, and occupants choose the evacuation routes depending on not only the distance from the exits, but also the distribution of the occupants around in their visual field. In Figure 9(b), some occupants originally located at the right part choose the left exit as their target. In these cases, the principle of taking the shortest route is not always useful when the distribution of occupants is not uniform at each area, while balancing the use ratio of each exit is benefit for improving evacuation efficiency. In practice, the

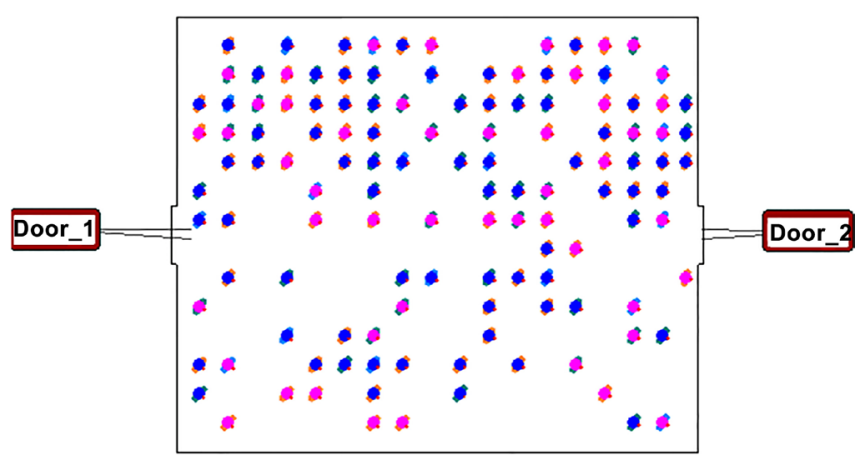

(a)

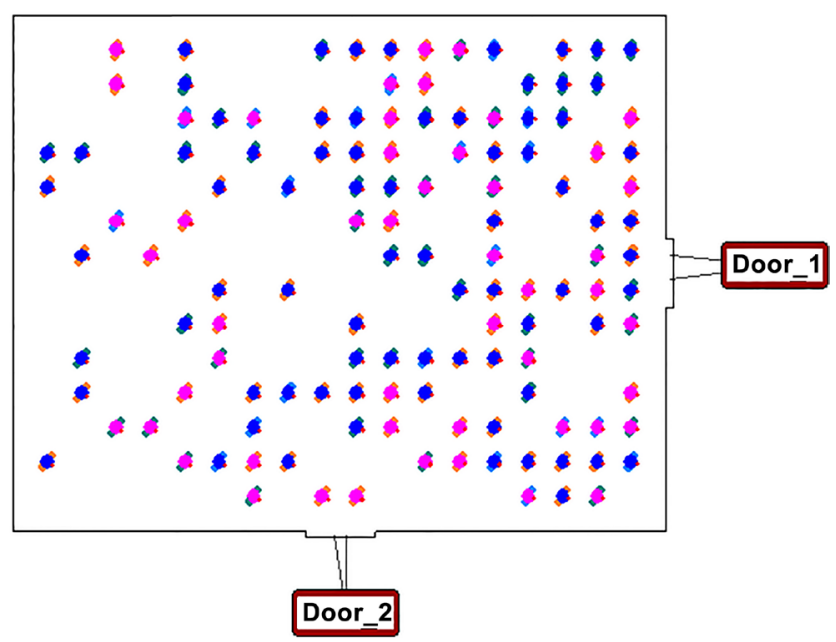

(c)

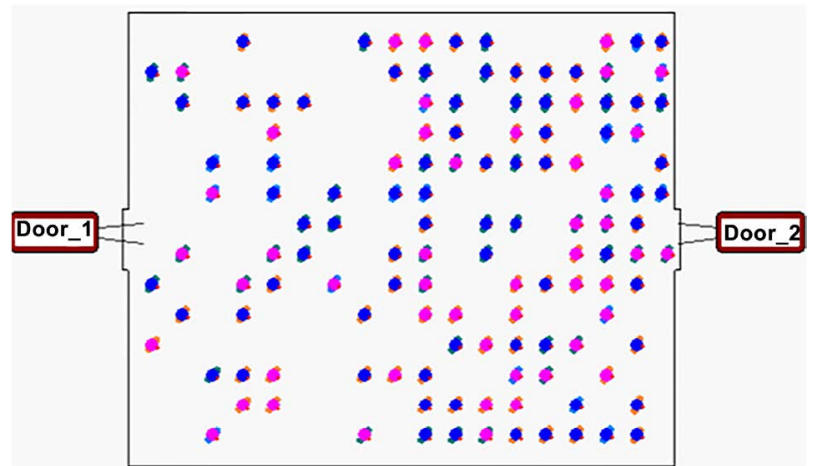

(b)

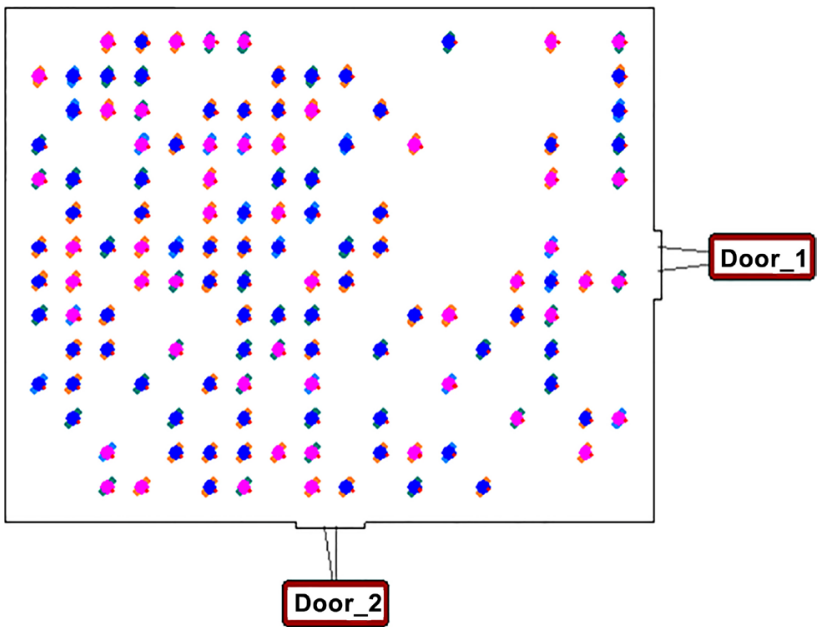

(d)

Figure 9. Original states with different layout of exits and density distribution, (a) opposite layout, the density of the upper half part is twice than that of the lower half part; (b) opposite layout, the density of the right half part is twice than that of the left half part; (c) adjacent layout, the density of the right half part is twice than that of the left half part; (d) adjacent layout, the density of the left half part is twice than that of the right half part. 
distribution and size of each exit should be adjusted according to the actual distribution of occupant density. More exits and greater exit width should be designed at the areas with higher occupant density.

\section{Summary}

In this paper, the software of building EXODUS is used to analyze the influence of some physical factors on evacuation including exit width, layout of exits, occupant density and distribution, and etc. The results and laws by EXODUS are compared with those by our CA simulations. The following conclusions can be obtained:

1) The evacuation pedestrian flow states in EXODUS simulation are very different from those in the CA simulation. In the beginning, some occupants away from the exits almost keep still in EXODUS simulation, while all occupants try to move toward the exits in the CA simulation. As far as the evacuation from a simple room is concerned, EXODUS is more reasonable than the CA model to exhibit the assembling state at the exit. It takes on a semicircular shape in EXODUS and a prolate shape in the CA model, respectively. As far as the evacuation in a long corridor after bottlenecks is concerned, the CA model is more reasonable than EXODUS. The occupants evenly distribute at the whole width of the corridor in the CA model, while the widths of pedestrian flow are limited to the width of the bottlenecks in EXODUS.

2) There is a critical value of exit width. If the value is smaller than the critical value, the pedestrian flow takes on a dense state and the evacuation time is very long. If the value is too big, evacuation time can only be reduced a little, and the use ratio of exit is reduced a lot. In practice, the value of exit width should be bigger than the critical value in order to ensure a dilute pedestrian flow and a safe evacuation. For example, the critical value is 4 for a room sized $18 \times 14$, and it is 10 for a room sized $50 \times 50$. The same laws can be obtained from both EXODUS and the CA model, but the evacuation times of the CA model are slightly greater than those of EXODUS.

3) The bigger the original occupant density, the longer the evacuation time is. They can be fitted as a linear relationship. This law can be obtained from both EXODUS and the CA simulation, but the evacuation times of the CA model are slightly smaller than those of EXODUS.

4) Both EXODUS and our CA model have certain intelligence. EXODUS simulation corresponds to the CA simulation with a visual field radius of 2 . The principle of following the shortest route (potential map) is applied both in EXODUS and the CA model. The CA model also considers the distribution of occupants and the visual field. If the distribution of occupant density is not uniform in each building part, balancing the use ratio of each exit should be the main principle.

\section{Acknowledgements}

Supported by the Natural Science Foundation of Shanghai (Grant No. 15ZR14- 
40900), the National Natural Science Foundation of China (Grant No. 51006072) and the develop project of master pilot of management science and Engineering (1021ZK14000100502, 4521ZK130059047). The authors deeply appreciate the supports.

\section{References}

[1] Zhao, C.M., Lo, S.M., Liu, M., et al. (2009) A Post-Fire Survey on the Pre-Evacuation Human Behavior. Fire Technology, 45, 71-95.

https://doi.org/10.1007/s10694-007-0040-6

[2] Shields, T.J. and Boyce, K.E. (2000) A Study of Evacuation from Large Retail Stores. Fire Safety Journal, 35, 25-49. https://doi.org/10.1016/S0379-7112(00)00013-8

[3] Spearpoint, M. (2004) The Effect of Pre-Evacuation on Evacuation Times in the Simulex Model. Journal of Fire Protection Engineering, 14, 33-53.

https://doi.org/10.1177/1042391504034742

[4] Fahy, R.F. and Proulx, M.G. (2001) Toward Creating a Database on Delay Times to Start Evacuation and Walking Speeds for Use in Evacuation Modeling. Proceedings of the 2nd International Symposium on Human Behaviour in Fire, Boston, 26-28 March 2001, 175-183.

[5] Togawa, K. (1955) Report No. 14. Building Research Institute, Tokyo.

[6] Melinek, S.J. and Booth, S. (1975) Current Paper CP 96/75. Building Research Establishment, Borehamwood.

[7] Pauls, J.L. (1978) Evacuation of High Rise Office Buildings. Buildings, 84.

[8] Nelson, H.E.B. and Mowrer, F.W. (2002) Emergency Movement. In: Dinenno, P.J. and Walton, W.D., Eds., SFPE Handbook of Fire Protection Engineering, National Fire Protection Association, Quincy, 367.

[9] Helbing, D. and Molnar, P. (1995) Social Force Model for Pedestrian Dynamics. Physical Review E, 51, 4282-4286. https://doi.org/10.1103/PhysRevE.51.4282

[10] Okazaki, S. and Matsushita, S. (1993) A Study of Simulation Model for Pedestrian Movement with Evacuation and Queuing. Proceedings of the International Conference on Engineering for Crowd Safety, London, 17-18 March 1993.

[11] Henderson, L.F. (1974) On the Fluid Mechanics of Human Crowd Motion. Transportation Research, 8, 509-515. https://doi.org/10.1016/0041-1647(74)90027-6

[12] Hughes, R.L. (2002) A Continuum Theory for the Flow of Pedestrians. Transportation Research Part B: Methodological, 36, 507-535. https://doi.org/10.1016/S0191-2615(01)00015-7

[13] Kalafatas, G. and Peeta, S. (2009) Planning for Evacuation: Insights from an Efficient Network Design Model. Journal of Infrastructure Systems, 15, 21-30. https://doi.org/10.1061/(ASCE)1076-0342(2009)15:1(21)

[14] Joo, J.K. and Kim, N.H. (2011) Modeling and Simulation of Emergent Evacuation Using Affordance-Based FSA Models. Industrial Engineering Journal, 37, 96-104. https://doi.org/10.7232/jkiie.2011.37.2.096

[15] Burstedde, C., Klauck, K., Schadschneider, A, et al. (2001) Simulation of Pedestrian Dynamics Using a Two-Dimensional Cellular Automaton. Physica A, 295, 507-525. https://doi.org/10.1016/S0378-4371(01)00141-8

[16] Li, W., Mao, L. and Bo, M. (2013) Incorporating Topography in a Cellular Automata Model to Simulate Residents Evacuation in a Mountain Area in China. Physica A, 392, 520-528. https://doi.org/10.1016/j.physa.2012.09.019 
[17] Alizadeh, R. (2011) A Dynamic Cellular Automaton Model for Evacuation Process with Obstacles. Safety Science, 49, 315-323. https://doi.org/10.1016/j.ssci.2010.09.006

[18] Ma, J., Lo, S.M. and Song, W.G. (2012) Cellular Automaton Modeling Approach for Optimum Ultra High-Rise Building Evacuation Design. Fire Safety Journal, 54, 5766. https://doi.org/10.1016/j.firesaf.2012.07.008

[19] Helbing, D., et al. (2003) Lattice Gas Simulation of Experimentally Studied Evacuation Dynamics. Physical Review E, 67, Article ID: 067101. https://doi.org/10.1103/PhysRevE.67.067101

[20] Guo, X.W., Chen, J.Q., Zheng, Y.C. and Wei, J.H. (2012) A Heterogeneous Lattice Gas Model for Simulating Pedestrian Evacuation. Physica A, 391, 582-592. https://doi.org/10.1016/j.physa.2011.07.055

[21] Lin, Y., et al. (2008) Agent-Based Simulation of Evacuation: An Office Building Case Study. In: Klingsch, W.W.F., et al., Eds., Pedestrian and Evacuation Dynamics, Springer, Berlin, 347-357.

[22] Heliövaara, S., Korhonen, T., Hostikka, S. and Ehtamo, H. (2012) Counterflow Model for Agent-Based Simulation of Crowd Dynamics. Building and Environment, 48, 89-100. https://doi.org/10.1016/j.buildenv.2011.08.020

[23] Nishinari, K., Kirchner, A., Namazi, A. and Schadschneider, A. (2003) Extended Floor Field CA Model for Evacuation Dynamics. IEICE Transactions on Information \& Systems, E87-D, 726-732.

[24] Gwynne, S., Galea, E.R., Lawrence, P.J. and Filippidis, L. (2001) Modelling Occupant Interaction with Fire Conditions Using the Building EXODUS Evacuation Model. Fire Safety Journal, 36, 327-357. https://doi.org/10.1016/S0379-7112(00)00060-6

[25] Zhao, D.L., Wang, J.H., Zhang, X.L. and Wang, X.Q. (2015) A Cellular Automata Occupant Evacuation Model Considering Gathering Behavior. International Journal of Modern Physics C, 26, Article ID: 1550089. https://doi.org/10.1142/s0129183115500898

[26] Zhao, D.L., Yang, L.Z. and Li, J. (2006) Exit Dynamics of Occupant Evacuation in an Emergency. Physica A, 363, 501-511. https://doi.org/10.1016/j.physa.2005.08.012

[27] Zhao, D.L., Yang, L.Z., Li, J., Zhu, Y. and Zou, L. (2006) Relationship between Performance-Based Design of Building Exits and State Transition of Pedestrian Flow during Occupant Evacuation. Journal of Fire Protection Engineering, 16, 269-281. https://doi.org/10.1177/1042391506061523

[28] Gay, J.P., Giovanni, T. and May, L. (2002) Streaming, Disruptive Interference and Power-Law Behavior in the Exit Dynamics of Confined Pedestrians. Physica A, 312, 609-618. https://doi.org/10.1016/S0378-4371(02)00987-1 
Submit or recommend next manuscript to SCIRP and we will provide best service for you:

Accepting pre-submission inquiries through Email, Facebook, LinkedIn, Twitter, etc. A wide selection of journals (inclusive of 9 subjects, more than 200 journals)

Providing 24-hour high-quality service

User-friendly online submission system

Fair and swift peer-review system

Efficient typesetting and proofreading procedure

Display of the result of downloads and visits, as well as the number of cited articles Maximum dissemination of your research work

Submit your manuscript at: http://papersubmission.scirp.org/

Or contact ojsst@scirp.org 